
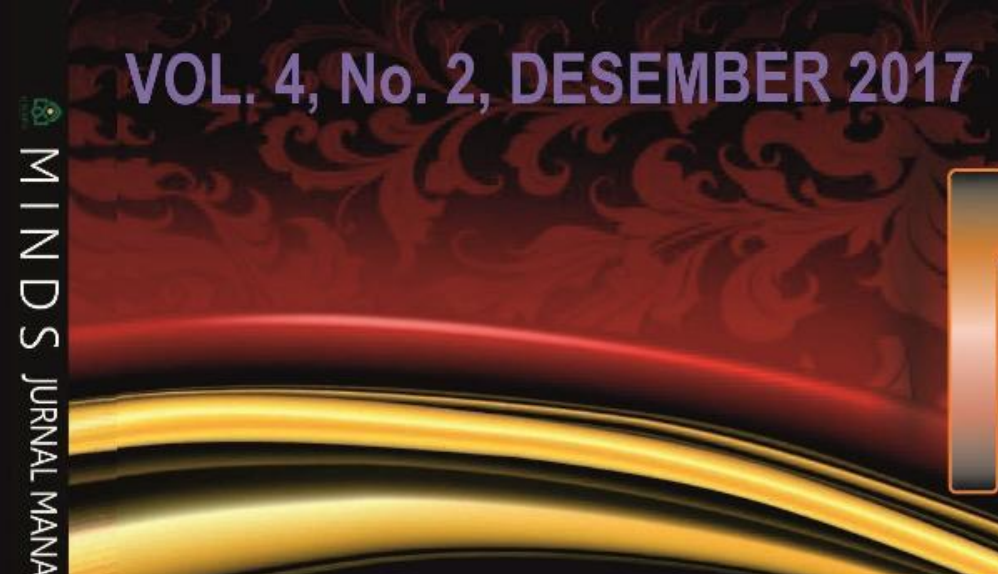

ShI

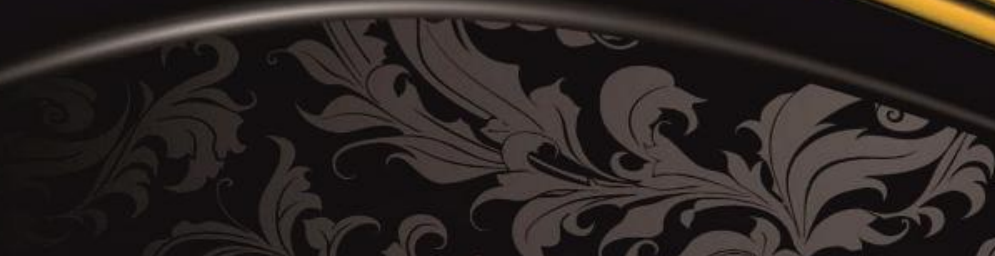

(ब)
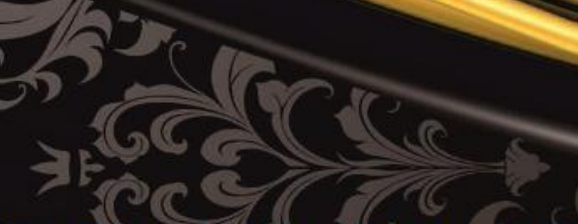

(C)

IDENTIFIKASI GAYA KEPEMIMPINAN PADA ORGANISASI RELAWAN PENANGGULANGAN BENCANA DI JAWA TIMUR

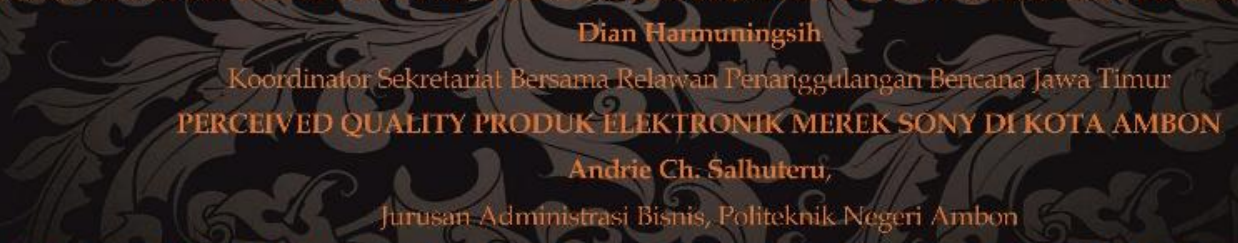

PENGARUH PROFITABILITAS, UIKUIDITAS, LEVERAGE, DAN FIRM SIZE TERHADAP KEBIJAKAN DIVIDEN PERUSAHAAN

$$
\begin{aligned}
& \text { DI INDEKS JII, PERIODE 2011-2015 } \\
& \text { Rika Dwi Ayu Parmitasari \& Hasrianto, }
\end{aligned}
$$

Jurusan Manajemen Fakultas Ekonomi dan Bisnis Islam, UIN Alauddin Makassar

FAKTOR YANG MEMENGARUHI KEPUASAN NASABAH BANK MUAMALAT CABANG AMBON

$$
\text { Gilman Pary, }
$$

Institut Agama Islam Negeri Ambon,

PENGARUH ATRIBUT PRODUK DAN PERILAKU PENCARIAN VARIASI TERHADAP PERILAKU MAHASISWA BERPINDAH MEREK PONSEL PADA FAKULTAS EKONOMI DAN BISNIS ISLAM Jusmiati \& Ahmad Efendi,

Jurusan Manajemen, Fakultas Ekonomi dan Bisnis Islam, UIN Alauddin Makassar

PENGARUH KUALITAS LAYANAN TERHADAP KEPUASAN PELANGGAN RUTE DOMESTIK GARUDA INDONESIA DI KOTA AMBON Saul Ronald Jacob Saleky,

Jurusan Administrasi Bisnis, Politeknik Negeri Ambon

PENGARUH STRES KERJA DAN IKLIM ORGANISASI TERHADAP TURNOVER KARYAWAN

$$
\text { Ludy Sapulette, }
$$

Jurusan Administrasi Bisnis, Politeknik Negeri Ambon

PENGARUH PEMBERDAYAAN DAN BUDAYA ORGANISASI TERHADAP PROFESIONALISME DOSEN

Ady Andardinata,

STIE Tri Dharma Nusantara

PENGARUH CSR, FIRM SIZE DAN INTEREST-BASED DEBT TERHADAP NILAI PERUSAHAAN PADA PERUSAHAAN MANUFAKTUR DI INDEKS JII, PERIODE 2010-2016

Wahidah Abdullah, Alim Syariati, \& Reskianti hamid

Fakultas Ekonomi dan Bisnis Islam, UNN Alauddin Makassar

ANALISIS DIMENSI KUALITAS PELAYANAN TERHADAP KEPUASAAN PASIEN PADA RSUD SYEKH YUSUF SUNGGUMINASA Asdi,

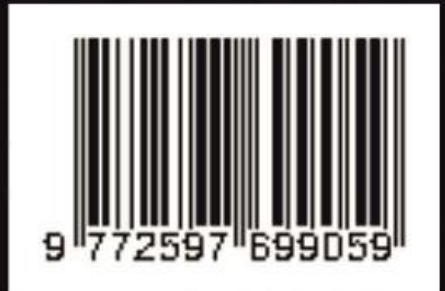

FEB, Lniversitas Muhammadiyah Makassar 
[Type text]

\section{KATA PENGANTAR}

Assalamualaikum WR. WB.

Puja dan puji syukur mari kita panjatkan ke hadirat Allah SWT, karena atas berkah dan karunia-Nya, maka Jurnal Manajemen dan Inspirasi (MINDS), Jurusan Manajemen, Fakultas Ekonomi dan Bisnis Islam, UIN Alauddin Makassar ini dapat diselesaikan. Salam dan shalawat kita haturkan kepada Nabi Muhammad SAW, sang pelita di tengah kejumudan dan kejahiliyahan, serta sumber informasi dan inspirasi yang terpercaya, al-Amiin. Terima kasih kami sampaikan kepada seluruh pihak yang terlibat dalam penyusunan jurnal Minds dari awal hingga akhir yang tidak dapat kami sebutkan satu persatu.

Adapun jurnal Minds merupakan titik kulminasi perwujudan kemampuan menulis tenaga pendidik yang berada di intra Fakultas maupun luar universitas. Tulisan akademik yang diharapkan menjadi contoh nyata jawaban dari berbagai fenomena empiris yang relevan dari sisi keilmuan Manajemen. Edisi kali ini, yaitu Vol. 4, No.2, 2017, mengupayakan adanya pengembangan dari sisi kualitas tulisan maupun sebaran wilayah penulis. Upaya ini diharapkan akan mendorong terciptanya proses yang lebih terukur baik dari penulis, mitra bestari, maupun penyunting, sehingga peningkatan kualitas publikasi ilmiah dapat diharapkan sebagai keluaran yang pasti.

Seiring dengan penerbitan jurnal ini, maka mewakili tim publikasi, saya menyampaikan rasa terima kasih yang sebesar-besarnya untuk seluruh penulis yang berpartisipasi dalam edisi kali ini, dan kepada para pembaca yang telah berkenan meluangkan waktunya untuk menelaah tulisan-tulisan yang termuat pada edisi kali ini.

Wassalamualaikum WR.WB.

Manajer Jurnal,

Dr. Alim Syariati, SE., M.Si. 


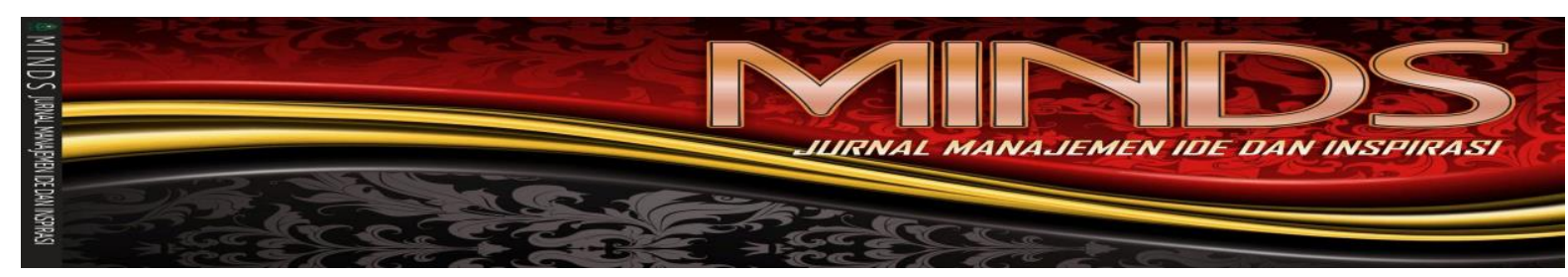

\section{DAFTAR ISI}

IDENTIFIKASI GAYA KEPEMIMPINAN PADA ORGANISASI

RELAWAN PENANGGULANGAN BENCANA DI JAWA TIMUR......

Dian Harmuningsih

Koordinator Sekretariat Bersama Relawan Penanggulangan Bencana Jawa Timur

PERCEIVED QUALITY PRODUK ELEKTRONIK MEREK SONY

DI KOTA AMBON

Andrie Ch. Salhuteru,

Jurusan Administrasi Bisnis, Politeknik Negeri Ambon

PENGARUH PROFITABILITAS, LIKUIDITAS, LEVERAGE, DAN

UKURAN PERUSAHAAN TERHADAP KEBIJAKAN DIVIDEN

SAHAM-SAHAM YANG TERDAFTAR PADA

JAKARTA ISLAMIC INDEX (JII) PERIODE TAHUN 2011-2015........

Rika Dwi Ayu Parmitasari \& Hasrianto,

Jurusan Manajemen Fakultas Ekonomi dan Bisnis Islam, UIN Alauddin Makassar

FAKTOR YANG MEMENGARUHI KEPUASAN NASABAH

BANK MUAMALAT CABANG AMBON

Gilman Pary,

Institut Agama Islam Negeri Ambon,

PENGARUH ATRIBUT PRODUK DAN PERILAKU PENCARIAN

VARIASI TERHADAP PERILAKU MAHASISWA BERPINDAH MEREK

PONSEL PADA FAKULTAS EKONOMI DAN BISNIS ISLAM............

Jusmiati \& Ahmad Efendi,

Jurusan Manajemen, Fakultas Ekonomi dan Bisnis Islam, UIN Alauddin Makassar

PENGARUH KUALITAS LAYANAN TERHADAP KEPUASAN PELANGGAN RUTE DOMESTIK GARUDA INDONESIA DI KOTA AMBON

Saul Ronald Jacob Saleky,

Jurusan Administrasi Bisnis, Politeknik Negeri Ambon

PENGARUH STRES KERJA DAN IKLIM ORGANISASI TERHADAP

TURNOVER INTENTION

Ludy Sapulette,

Jurusan Administrasi Bisnis, Politeknik Negeri Ambon

PENGARUH PEMBERDAYAAN DAN BUDAYA ORGANISASI

TERHADAP PROFESIONALISME DOSEN.

Ady Andardinata,

STIE Tri Dharma Nusantara 
PENGARUH CORPORATE SOCIAL RESPONSIBILITY (CSR), UKURAN PERUSAHAAN DAN INTEREST BASED DEBT (IBD) TERHADAP NILAI PERUSAHAAN PADA PERUSAHAAN MANUFAKTUR (YANG TERDAFTAR DI JAKARTA ISLAMIC INDEX PERIODE 2010-2016)..... Wahidah Abdullah, Alim Syariati, \& Reskianti hamid

Fakultas Ekonomi dan Bisnis Islam, UIN Alauddin Makassar

ANALISIS DIMENSI KUALITAS PELAYANAN TERHADAP KEPUASAAN PASIEN PADA RSUD SYEKH YUSUF SUNGGUMINASA

Asdi, FEB,

Universitas Muhammadiyah Makassar 


\title{
PERCEIVED QUALITY PRODUK ELEKTRONIK MEREK SONY DI KOTA AMBON
}

\author{
Andrie Ch. Salhuteru*
}

\begin{abstract}
ABSTRAK
Penelitian ini bertujuan untuk menganalisis faktor-faktor harga yang berpengaruh terhadap perceived quality produk elektronik merek Sony di Kota Ambon. Data penelitian ini dikumpulkan menggunakan kuesioner yang dibagikan kepada konsumen yang menggunakan produk elektronik merek Sony khususnya kategori audio-video di Kota Ambon. Data yang dikumpulkan diolah menggunakan SPSS 21 dan selanjutnya dianalisis menggunakan analisis regresi berganda. Hasilnya menunjukan variabel price premium berpengaruh positif dan signifikan terhadap perceived quality produk elektronik merek Sony di Kota Ambon. Karena itu direkomendasikan agar pihak pemasar senantiasa dapat memerhatikan kebijakan harga yang diterapkan atas produk yang ditawarkannya.
\end{abstract}

Kata kunci : price premium, perceived price, price deal, perceived quality

ABSTRACT

This study aims to analyze the price factors that affect the perceived quality of Sony's electronic products in the city of Ambon. The data of this study were collected using questionnaires distributed to consumers using Sony brand electronics products, especially audio-video category in Ambon City. The collected data was processed using SPSS 21 and then analyzed using multiple regression analysis. The result shows that the premium price variable has a positive and significant effect on perceived quality of Sony's electronic products in Ambon City. Therefore it is recommended that the marketer always be able to pay attention to the pricing policy applied on the products it offers.

Keywords: price premium, perceived price, price deal, perceived quality

PENDAHULUAN

Para praktisi para akademisi di bidang pemasaran telah menunjukkan minat yang sangat besar terhadap faktor-faktor yang mempengaruhi maupun menentukan ekuitas merk (brand equity) (del Rio et al. 2001). Brand equity oleh Marketing Science Institute (1988) sebagaimana dikutip oleh Chay (1990) dan del Rio et al. (2001) didefinisikan sebagai serangkaian hubungan dan perilaku pada pelanggan / konsumen pengguna merk, anggota saluran distribusi dan perusahaan induk yang memudahkan merk untuk memeroleh volume penjualan bahkan tingkat keuntungan yang lebih besar apabila dibandingkan dengan tanpa adanya merk pada produk, dan hal-hal yang mampu

* Jurusan Administrasi Bisnis, Politeknik Negeri Ambon, Jalan Ir. M. Putuhena,Wailela, Ambon : andriesalhuteru@ymail.com 
memberikan merk suatu keunggulan yang kuat, berkesinambungan dan kompetitif dibandingkan para pesaingnya. Dengan adanya nilai produk bagi konsumen, maka penjualan dapat sepanjang waktu seiring dengan kuatnya nama merk.

Upaya-upaya untuk mengukur ekuitas merk secara umum berfokus pada identifikasi dan pengembangan komponenkomponen ekuitas merk dari perspektif yang berbeda-beda (konsumen, perusahaan, saluran distribusi dan pasar modal), pendekatan yang berbeda-beda (mental, perilaku, dan keuangan/ekonomi), dan metode yang berbeda-beda (pendekatan komparatif berbasiskan merk, kegiatan pemasaran, analisis konjoin, pendekatan residual, dan pendekatan valuasi) (Keller, 1993).

Ekuitas merk (brand equity) dapat dipandang dan dianalisis dari perspektif konsumen, distributor, perusahaan yang menjadi produsen bahkan pasar modal. Namun, sumber yang paling kuat dari nilai merk (brand value) adalah pengguna akhir (end user). Makin positif penerimaan pengguna akhir terhadap suatu merk, maka makin tinggi kesadaran merk (brand awareness) dan loyalitas konsumen. Hal ini kemudian mampu membuat perusahaan memeroleh marjin yang lebih tinggi, pangsa pasar yang lebih besar, tanggapan konsumen terhadap peningkatan harga yang makin tidak elastis (konsumen makin tidak peka terhadap harga), makin berkurangnya kerentanan (volatility) terhadap aktivitas pesaing bahkan mampu membuat perusahaan meningkatkan aktivitas pemasarannya (Myers 2003).

Ekuitas merk (brand equity) yang tinggi berimplikasi konsumen memiliki hubungan yang positif dengan nama merk, bahkan melebihi produk itu sendiri secara harafiah (Yoo et. al, 2000), memengaruhi konsumen dalam menentukan pilihannya (Chen, 2001), serta membuat konsumen lebih memilih produk dengan merk tertentu dibandingkan produk yang sama dengan merk lain (Seetharaman, et. al, 2001).

Variabel yang telah digunakan oleh Yoo et al. (2000) akan diteliti dalam penelitian ini adalah harga (perceived price), price deal, perceived quality dan brand equity (ekuitas merk). Variabel anteseden yaitu harga (perceived price) dalam penelitian ini dikaji melalui perspektif konsumen atau harga menurut pendapat konsumen (subyektif), sedangkan price deal dikaji sebagai bentuk promosi yang dilakukan perusahaan yang dirasakan oleh konsumen dalam bentuk potongan harga.

Lebih lanjut penelitian ini menambahkan variabel price premium dari hasil penelitian Apelbaum, et. al (2003) yang menyimpulkan price premium berpengaruh terhadap perceived quality. Price premium cenderung mengacu pada hal-hal yang berkaitan dengan bagaimana suatu produk dapat dijual dengan harga yang tinggi. Price premium berhubungan dengan perceived quality (Seetharaman, et. al, 2001)

Berdasarkan latar belakang di atas maka dalam penelitian ini, upayaupaya pemasaran (marketing efforts) seperti harga (perceived price), price premium dan price deal akan dikaji kembali pengaruhnya terhadap perceived quality dan dampaknya pada ekuitas merk (brand equity) untuk produk elektronik dengan merk Sony. Produk elektronik dikaji dalam penelitian ini karena produk 
elektronik merupakan produk yang berbasiskan pada teknologi. Pada masa sekarang ini produk berbasiskan teknologi sangat diminati oleh banyak orang dan banyak produsen yang saling bersaing di pasar produk berbasiskan teknologi. Alasan lainnya adalah bahwa telah banyak penelitian mengenai brand equity untuk produk elektronik (teknologi) namun penelitian tersebut dilakukan pada era lebih dari lima tahun yang lalu, misalnya penelitian Biswas dan Sherrell (1993) dan Chen (2001).

Penelitian Biswas dan Sherrel (1993) mengkaji produk dengan merk yang saat ini sangat terbatas peredarannya di Indonesia misalnya Technics. Padahal peta persaingan industri elektronik (produk berbasiskan teknologi) saat ini telah berubah. Sementara itu produk elektronik dengan merk Sony dikaji dalam penelitian ini karena merk ini merupakan merk yang paling melekat di benak konsumen. Lebih lanjut merk ini juga menjadi acuan bagi penelitian terdahulu misalnya penelitian Biswas dan Sherrel (1993) serta merk ini memiliki high image brand dengan harga jual di atas rata-rata yang cocok untuk diteliti dalam kaitannya dengan variabel-variabel yang digunakan dalam penelitian ini.

Penelitian ini bertujuan untuk mengkaji pengaruh dari faktor-faktor harga (price premium, perceived price, dan price deal terhadap perceived quality produk elektronik merek Sony di Kota Ambon.

Dari uraian di atas, masalah yang akan dibahas dalam penelitian ini adalah sebagai berikut "

1. Apakah price premium berpengaruh terhadap perceived quality produk elektronik merek Sony di Kota Ambon.

2. Apakah perceived price berpengaruh terhadap perceived quality produk elektronik merek Sony di Kota Ambon.

3. Apakah price deal berpengaruh terhadap perceived quality produk elektronik merek Sony di Kota Ambon.

Hasil dari penelitian ini diharapkan dapat memberi masukan pemasar produk elektronik secara umum dan khususnya merek Sony dalam mempertimbangkan kebijakan harga produk yang ditawarkan kepada konsumennya.

\section{TINJAUAN TEORITIS}

Ekuitas Merek (Brand Equity)

Aaker (1991) menyatakan bahwa nilai tambah yang diberikan suatu nama merk terhadap suatu produk seringkali disebut dengan istilah ekuitas merk (brand equity). Kebanyakan tulisan mengenai ekuitas merk lebih memperhatikan masalahmasalah definisional (Cobb-Walgren et al. 1995). Ekuitas merk dapat didiskusikan dari perspektif investor, produsen ataupun konsumen. Investor memiliki motivasi finansial untuk meningkatkan nilai suatu nama merk agar nilai perusahaan juga meningkat. Di lain pihak, produsen dan pengecer termotivasi oleh implikasi strategis dari ekuitas merk (Keller 1993).

Bagi produsen, ekuitas merk memberikan keunggulan yang memungkinkan perusahaan menciptakan volume dan marjin yang lebih besar. 
Ekuitas merk menyediakan platform yang kuat untuk memerkenalkan produk baru dan memertahankan merk dari serangan pesaing. Dari perspektif perdagangan, ekuitas merk memberikan sumbangan pada citra menyeluruh dari suatu perusahaan.

Hal-hal tersebut di atas tidak akan berarti jika merk tidak memiliki arti bagi konsumen. Dengan kata lain, hanya akan ada nilai bagi produsen, investor dan pengecer apabila terdapat nilai bagi konsumen (Farquhar 1989, Crimmins 1992). Sehingga amatlah penting untuk memahami bagaimana nilai merk (brand value) diciptakan dalam pikiran konsumen dan bagaimana hal tersebut diterjemahkan dalam perilaku memilih.

Sebagaimana dinyatakan sebelumnya, bahwa ekuitas merk telah didefinisikan dalam berbagai cara tergantung pada tujuannya. Mengingat penelitian ini lebih ditujukan untuk konsumen maka fokus pembahasannya adalah pada ekuitas merk berbasis konsumen. Keller (1993) mendefinisikan ekuitas merk berbasis konsumen sebagai pengaruh diferensial dari pengetahuan merk terhadap tanggapan konsumen pada pemasaran suatu merk. Tiga konsep penting yang muncul dari definisi ini adalah pengaruh diferensial, pengetahuan merk, dan tanggapan konsumen. Pengaruh diferensial ditentukan dengan membandingkan tanggapan konsumen terhadap suatu merk dengan produk sejenis dengan merk lain atau tanpa merk.

Pengetahuan merk didefinisikan dengan istilah kesadaran merk dan citra merk dan dikonseptualisasikan menurut karakteristik dan hubungan merk yang telah dijelaskan sebelumnya. Tanggapan konsumen dijabarkan dengan istilah persepsi, preferensi dan perilaku konsumen yang muncul dari aktivitas bauran pemasaran. Sehingga dapat dikatakan bahwa suatu merk memiliki ekuitas merk berbasis konsumen yang positif (negatif) jika konsumen bereaksi lebih (kurang) menguntungkan pada produk, harga, promosi atau distribusi apabila dibandingkan dengan reaksi konsumen pada produk sejenis dengan merk lain.

\section{Perceive Quality}

Perceived quality adalah dimensi lain dari nilai merk yang sangat penting bagi konsumen untuk memilih barang dan jasa yang akan dibelinya (Aaker 1991; Zeithaml 1988). Penting untuk dicatat bahwa kualitas produk adalah sumber daya perusahaan yang penting untuk mencapai keunggulan bersaing (Aaker 1989 dalam Baldauf et al. 2003).

Perceived quality didefinisikan oleh Zeithaml (1988) sebagai penilaian (persepsi) konsumen terhadap keunggulan suatu produk secara keseluruhan. Dibandingkan dengan penggantinya. Dari definisi ini maka diketahui bahwa perceived quality adalah kemampuan produk untuk dapat diterima dalam memberikan kepuasan apabila dibandingkan secara relatif dengan alternatif yang tersedia.

Perceived quality yang tinggi menunjukkan bahwa konsumen telah menemukan perbedaan dan kelebihan produk tersebut dengan produk sejenis setelah melalui jangka waktu yang lama. Zeithaml (1988) menyatakan bahwa perceived quality adalah komponen dari nilai merk oleh karena itu perceived 
quality yang tinggi akan mendorong konsumen untuk lebih memilih merk tersebut dibandingkan dengan merk pesaing.

Perceived quality dapat diukur dari indikator overall quality, functional, reliable, dan durable (Yoo et al. 2000 dan Dodds et al. 1991).

\section{Price Premium}

Ketika suatu merk mampu dijual di atas harga rata-rata atau dengan harga yang lebih tinggi dibandingkan produk sejenis maka dikatakan bahwa merk tersebut mampu mencapai price premium. Price premium cenderung berhubungan dengan produk termasuk di antaranya adalah kualitas produk. Produk yang berharga tinggi biasanya dihasilkan dengan biaya yang relatif lebih tinggi pula. Setharaman et al. (2003) mengemukakan price premium berhubungan dengan perceived quality. Hal ini dapat terjadi karena konsumen seringkali menggunakan harga sebagai indikator kualitas. Makin tinggi harga (price premium) makin tinggi kualitas dibandingkan produk lain (Agarwal dan Teas 2002).

Setharaman, et. al (2001) melakukan kajian mengenai faktor-faktor yang memengaruhi konsumen untuk mau membayar lebih bagi suatu merk. Mereka menemukan perceived quality berhubungan positif dengan hal tersebut. Kajian serupa juga telah dilakukan oleh Rao dan Monroe (1989) yang menggunakan meta analisis bagi produk konsumsi, harga berhubungan positif dengan perceived quality dan nama merk berhubungan positif dengan perceived quality.

Namun dengan menggunakan desain eksperimental ditemukan bahwa manipulasi harga memiliki pengaruh yang signifikan terhadap harga dan perceived quality. Penelitian Setharaman et. al (2001) menemukan price premium berpengaruh terhadap perceived quality.

Variabel price premium dapat diukur melalui indikator-indikator yang dikembangkan oleh Setharaman et al. (2001) dan Agarwal dan Teas (2002) yaitu perbandingan harga (relative price), kepatutan dan keaslian.

\section{Perceived Price}

Menurut Zeithaml (1988), dari perspektif konsumen, harga adalah perihal apa yang diberikan atau dikorban dalam upaya untuk memeroleh suatu produk. Jacoby dan Olson (Zeithaml, 1988) membedakan harga menjadi harga obyektif (harga aktual dari suatu produk) dan perceived price (harga menurut konsumen). Penelitian-penelitian yang telah dilakukan menemukan bahwa konsumen tidak selalu mengingat harga aktual dari suatu produk, namun mereka melihat harga menurut pendapat mereka dan bagi mereka harga hanya dikategorikan murah atau mahal (Zeithaml, 1988). Oleh sebab itu harga yang digunakan dalam penelitian ini adalah perceived price.

Konsumen menggunakan harga sebagai indikator penting dalam melihat suatu kualitas produk. Produk bermerk dengan harga yang tinggi seringkali dianggap mempunyai kualitas yang lebih tinggi apabila dibandingkan dengan produk bermerk tetapi dengan harga yang lebih murah (Blattberg dan Winniewski 1989; Dodds et al. 1991; Kamakura dan Russell 1993).

Dodds et al. (1991) dan Rao dan Monroe (1989) menyatakan konsumen cenderung menggunakan harga sebagai indikator kualitas bagi produk yang 
secara relatif lebih mahal. Seiring dengan meningkatnya harga maka resiko adanya kesalahan menaksir akan meningkat dan pembeli yang belum terbiasa dengan produk akan menggunakan idiom "what you pay is what you get" dalam memilih produk. Oleh karena itu harga (perceived price) secara positif mempengaruhi perceived quality. Agarwal dan Teas (2002) juga menyatakan bahwa pengaruh harga (perceived price) terhadap perceived quality telah didemonstrasikan pada banyak kajian.

Dawar dan Parker (1994) bahkan mengamati bahwa fenomena tersebut dalam konteks internasional dan menemukan bahwa tidak ada batasan budaya dalam kesimpulannya. Hal yang sama juga dikemukakan oleh Rao dan Monroe (1989). Rao dan Monroe (1989) menyatakan bahwa hubungan positif antara harga (perceived price) dan perceived quality telah didukung oleh banyak penelitian.

\section{Price Deal}

Price deal (bisa dalam bentuk pengurangan harga jangka pendek seperti penjualan khusus, kupon, potongan harga, rebat dan refund) seringkali dipercayai dapat menurunkan ekuitas merk walaupun mampu meningkatkan penjualan di jangka pendek (Yoo et al. 2000). Price deal dalam bentuk potongan harga bukanlah jalan yang tepat untuk membangun ekuitas merk karena hal ini mudah ditiru dan dilawan oleh pesaing dan hanya meningkatkan kinerja jangka pendek dengan mendorong penjualan dan menggunakan momen perindahan merk sementara saja (Gupta 1988).

Di jangka panjang, reduksi harga (price deal) dapat membawa konsumen kepada citra merk berkualitas rendah. Lebih lanjut, di jangka panjang jika frekuensi dari price deal cukup tinggi maka malah akan membawa resiko merk di jangka panjang karena akan membingungkan konsumen antara harga normal dan price deal yang mengakibatkan adanya citra ketidak stabilan kualitas (Winner 1986; Biswas dan Sherrell 1993).

Grewal et al. (1998) menyatakan bahwa price deal sangat mungkin untuk memiliki pengaruh yang negatif terhadap persepsi akan kualitas. Persepsi kualitas dapat dijelaskan dengan menggunakan teori persepsi diri, salah satu jenis teori atribusi (attribution theory) yang menggambarkan bagaimana konsumen menjelaskan suatu kejadian. Jika konsumen membeli produk dengan yang lebih murah mereka seringkali menganggap bahwa produk tersebut dijual lebih murah karena memiliki kualitas yang lebih buruk.

Variabel price deal dapat diukur melalui indikator yang digunakan oleh Yoo et al. (2000) yaitu frekuensi price deal, presentasi price deal dan price deal reasonable.

Dari uraian di atas, dapat dikembangkan suatu kerangka konseptual pada Gambar 1. 


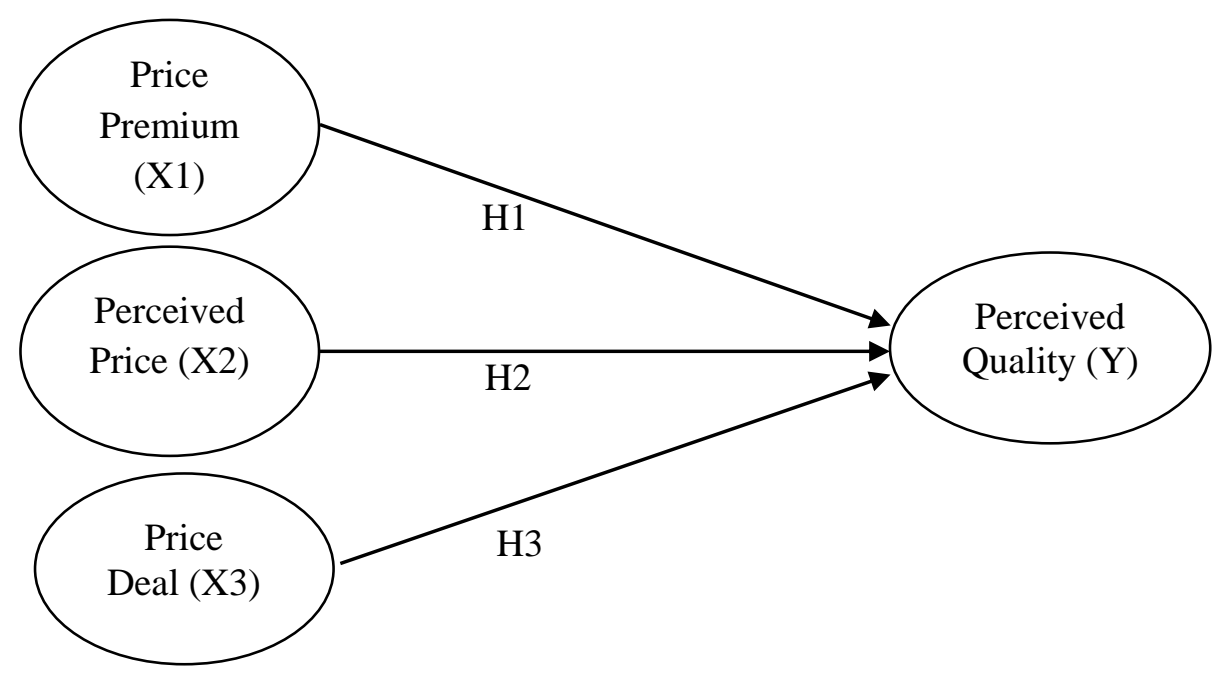

Gambar 1. Kerangka Konseptual Penelitian

Selanjutnya dari uraian di atas, hipotesis yang akan diuji dalam penelitian ini dapat dirumuskan sebagai berikut :

1. Price premium berpengaruh positif dan signifikan terhadap perceived quality.

2. Perceived price berpengaruh positif dan signifikan terhadap perceived quality

3. Price deal berpengaruh negatif terhadap perceived quality

\section{METODE PENELITIAN}

Penelitian ini termasuk dalam jenis penelitian explanatory yang menjelaskan hubungan kausal dan pengujian hipotesa. Penelitian ini merupakan explanatory research dengan pendekatan kausalitas, yaitu penelitian yang ingin mencari penjelasan dalam bentuk hubungan sebab akibat (cause - effect) antar beberapa konsep atau beberapa variabel atau beberapa strategi yang dikembangkan dalam manajemen (Ferdinand, 2006). Penelitian ini dilakukan di Kota Ambon selama bulan bulan Agustus - September 2017.

Data primer dalam penelitian ini diperoleh berdasarkan daftar pertanyaan yang diberikan secara tertulis konsumen pengguna produk elektronik merek Sony khususnya pada kategori produk audio-video yaitu televisi, kamera, handycam, dan kamera digital di Kota Ambon. Sementara data sekunder diperoleh melalui literatur, jurnal ilmiah, majalah maupun data dokumen yang sekiranya diperlukan untuk penelitian ini.

Untuk penelitian ini populasi yang digunakan adalah semua pengguna produk elektronik merek Sony khususnya pada kategori produk audio-video yaitu televisi, kamera, handycam, dan kamera digital di Kota Ambon. Mengingat ukuran populasi yang tidak diketahui secara pasti, teknik pengambilan sampel yang digunakan mengacu pada Hair et. al 1998, yaitu jumlah sampel minimal yang digunakan sebanyak 5 kali dari jumlah parameter yang dipergunakan dalam penelitian. Penelitian ini menggunakan 13 parameter sehingga jumlah sampel minimal yang digunakan adalah sebanyak 5 $x 13=65$. 
Pengumpulan data dilakukan dengan menggunakan daftar pertanyaan tertutup, untuk mendapatkan data tentang indikator-indikator dari price premium, perceived price, price deal, dan perceived quality. Pernyataan-pernyataan dibuat dengan menggunakan skala 1 (Sangat Tidak Setuju) - 5 (Sangat Setuju) untuk mendapatkan data yang bersifat interval. Teknik analisis yang digunakan dalam penelitian ini adalah analisis regresi berganda (multiple regression analysis) dengan formula :

$$
\mathrm{Y}=\mathrm{b} 0+\mathrm{b}_{1} \mathrm{X}_{1}+\mathrm{b}_{2} \mathrm{X}_{2}+\mathrm{b} 3 \mathrm{X}_{3}+\varepsilon
$$

di mana :

$\mathrm{Y}=$ Perceived Quality

$\mathrm{X}_{1}=$ Price Premium

$\mathrm{X}_{2}=$ Perceived Price

$\mathrm{X}_{3}=$ Price Deal

$\mathrm{b}_{0}=$ Konstanta

$b_{1}=$ Koefisien regresi $X_{1}$

$b_{2}=$ Koefisien regresi $X_{2}$

$b_{3}=$ Koefisien regresi $X_{3}$

$\varepsilon=$ Nilai residual

\section{PEMBAHASAN}

\section{Karakteristik Responden}

Responden penelitian ini berjumlah 65 orang konsumen pengguna produk elektronik merek Sony kategori audio-video di Kota Ambon Ambon. Hasil tabulasi menunjukan bahwa mereka terdiri dari 43 orang $(66,2 \%)$ laki-laki dan 22 orang $(33,8 \%)$ perempuan. Menurut kelompok usia, responden penelitian ini terdiri dari 13 orang $(20,0 \%)$ berusia kurang dari 30 tahun, 35 orang $(53,8 \%)$ berusia antara $21-50$ tahun, dan selebihnya sebanyak 17 rang $(26,2 \%)$ berusia lebih dari 50 tahun. Selanjutnya responden penelitian ini yang memiliki pendidikan terakhir SMA/Sederajat sebanyak 16 orang $(24,6 \%)$, diploma sebanyak 22 orang (33, 8\%), sarjana sebanyak 24 orang $(36,9 \%)$, dan pascasarjana sebanyak 3 orang $(4,6 \%)$. Dari jenis pekerjaan, responden yang bekerja sebagai pegawai negeri sipil sebanyak 15 orang $(23,1 \%)$, pegawai swasta sebanyak 22 orang $(33,8 \%)$, anggota TNI/Polri sebanyak 13 orang $(20,0 \%)$, professional sebanyak 9 orang $(13,8 \%)$, serta pelajar dan mahasiswa sebanyak 6 orang $(9,2 \%)$. Sementara itu, responden yang memiliki penghasilan per bulan kurang dari Rp. 3.000.000,- per bulan sebanyak 1 orang (1,5\%), antara Rp 3.000.000,- sampai dengan Rp 6.000.000,- sebanyak 27 orang (41,5\%), lebih dari Rp. 6.000.000,- sebanyak 37 orang (56,9\%). Responden yang telah menggunakan produk elektronik merek Sony kurang dari 5 tahun sebanyak 15 orang $(23,1 \%)$, antara 5 sampai dengan 10 tahun sebanyak 34 orang (52,3\%), dan lebih dari 10 tahhun sebanyak 24,6). Sedangkan cara pembelian yang digunakan oleh responden terdiri dari pembelian secara tunai sebanyak 31 orang $(4, \%)$, dan secara kredit sebanyak 34 orang $(52,3)$.

\section{Hasil Penelitian}


Analisis regresi berganda digunakan untuk mengukur besarnya kontribusi atau pengaruh variabel bebas terhadap variabel terikat. Sebelum dilakukan analisis regresi berganda, terlebih dahulu dilakukan pengujian terhadap validitas dan reliabilitas data yang dikumpulkan melalui kuesioner. Hasil pengujian validitas menunjukan semua indikator yang digunakan dalam penelitianini valid dengan nilai koefisien $>0,6$ dan signifikansi 0,000. Selanjutnya hasil pengujian reliabiitas juga menunjukan semua variabel adalah reliabel untuk digunakan dalam melakukan pengukuran, yang ditunjukan melalui nilai Cronbach Alpha >0,60.

Ringkasan hasil pengujian persamaan regresi dalam penelitian ini dalam bentuk persamaan regresi berganda disajikan dalam tabel berikut.

Tabel 1. Ringkasan Hasil Regresi

\begin{tabular}{|c|c|c|c|c|c|c|c|}
\hline \multirow{2}{*}{\multicolumn{3}{|c|}{ Model }} & \multicolumn{2}{|c|}{$\begin{array}{c}\text { Unstandardized } \\
\text { Coefficients }\end{array}$} & \multirow{2}{*}{$\begin{array}{c}\text { Standardized } \\
\text { Coefficients } \\
\text { Beta } \\
\end{array}$} & \multirow[b]{2}{*}{$\mathrm{t}$} & \multirow[b]{2}{*}{ Sig. } \\
\hline & & & B & Std. Error & & & \\
\hline \multirow[t]{8}{*}{1} & (Const & & .171 & .178 & & .964 & .339 \\
\hline & Price $\mathrm{P}$ & mium & .756 & .071 & .521 & 10.673 & .000 \\
\hline & Perceiv & d Price & .128 & .056 & .677 & 2.273 & .027 \\
\hline & Price D & & .085 & .074 & .013 & 1.153 & .254 \\
\hline & $\mathrm{R}$ & $=0,946$ & & & & & \\
\hline & $\mathrm{R}^{2}$ & $=0,894$ & & & & & \\
\hline & $F_{\text {hitung }}$ & $=172,229$ & & & & & \\
\hline & Sig & $=0,000$ & & & & & \\
\hline
\end{tabular}

Sumber : Hasil Pengolahan, 2017

Berdasarkan tabel ' di atas, model persamaan yang dihasilkan penelitian ini dalam bentuk persamaan regresi berganda adalah :

$$
Y=0,171+0,756 X_{1}+0,128 X_{2}+0,085 X_{3}+0,054
$$

Dari hasil persamaan regresi tersebut di atas maka dapat dijelaskan sebagai berikut :

$\mathrm{b}_{0}=0,171$ merupakan nilai konstanta, artinya tanpa adanya persepsi konsumen atas price premium, perceived price, dan price deal maka perceived quality produk elektronik merek Sony di Kota Ambon adalah sebesar 0,171 atau $17,1 \%$.

$\mathrm{b}_{1}=0,756$ menunjukkan apabila persepsi konsumen atas price premium produk elektronik merek Sony di Kota Ambon ditingkatkan, sedangkan faktor-faktor lainnya tetap maka akan memengaruhi perceived quality sebesar 0,756 atau $75,6 \%$.

$\mathrm{b}_{2}=0,128$ menunjukkan persepsi konsumen atas perceived price produk elektronik merek Sony di Kota Ambon ditingkatkan, sedangkan faktorfaktor lainnya tetap maka akan memengaruhi perceived quality sebesar 0,128 atau $12,8 \%$.

$b_{3}=0,085$ menunjukkan persepsi konsumen atas price deal produk elektronik merek Sony di Kota Ambon ditingkatkan, sedangkan faktor-faktor lainnya tetap maka akan memengaruhi perceived quality sebesar 0,085 atau 8,5\%. 
$\varepsilon=0,054$ menunjukan nilai residu atau nilai pengaruh dari variabel lain yang tidak diikutkan dalam penelitian ini.

Nilai $\mathrm{R}=0,946$ atau $94,6 \%$ menunjukan pengaruh price premium, perceived price dan price deal terhadap perceived quality, sedangkan nilai koefisien determinasi $\mathrm{R}^{2}=0,894$ menunjukan price premium, perceived price, dan price deal secara bersama-sama memengaruhi perceived quality sebesar 89,4\%, sedangkan sisanya 5,4\% dipengaruhi oleh faktor lain yang tidak ikut diteliti. Hasil ini menunjukan persepsi responden atas price premium, perceived price, dan price deal memberikan kontribusi sebesar $48,7 \%$ terhadap pembentukan perceived quality pengguna produk elektronik merek Sony di Kota Ambon.

Tabel 1 menunjukan nilai t-hitung variabel price premium sebesar 10.673 dengan signifikansi 0,000 sementara nilai t-tabel adalah 2,65 dengan demikian nilai t-hitung $>\mathrm{t}$-tabel, sehingga hipotesis 1 yang diajukan dalam penelitian ini dapat diterima, di mana price premium berpengaruh positif dan signifikan terhadap perceived quality produk elektronik merek Sony di Kota Ambon.

Kemudian nilai t-hitung variabel perceived price sebesar 2.273 dengan signifikansi 0,027 sementara nilai t-tabel adalah 2,65 dengan demikian nilai thitung < t-tabel, sehingga hipotesis 2 yang diajukan dalam penelitian ini tidak dapat diterima, di mana perceived price berpengaruh positif tetapi tidak signifikan terhadap perceived quality produk elektronik merek Sony di Kota Ambon.

Selanjutnya nilai t-hitung variabel price deal sebesar 1.153 dengan signifikansi 0,254 sementara nilai t-tabel adalah 2,65 dengan demikian nilai thitung < t-tabel, sehingga hipotesis 3 yang diajukan dalam penelitian ini tidak dapat diterima, di mana price deal berpengaruh positif tetapi tidak signifikan terhadap perceived quality produk elektronik merek Sony di Kota Ambon.

\section{Pembahasan}

Temuan penelitian ini menunjukan adanya pengaruh yang positif dari semua variabel harga terhadap perceived quality. Sebelumnya Dodds et al. (1991) dan Rao dan Monroe (1989) menyatakan konsumen cenderung menggunakan harga sebagai indikator kualitas bagi produk yang secara relatif lebih mahal. Seiring dengan meningkatnya harga maka resiko adanya kesalahan menaksir akan meningkat dan pembeli yang belum terbiasa dengan produk akan menggunakan idiom "what you pay is what you get" dalam memilih produk. Hasil penelitian ini menunjukan adanya pengaruh yang positif dan signifikan dari variabel price premium terhadap perceived quality. Hal ini berarti konsumen seringkali memersepsikan kualitas produk dengan harga yang premium. Hal ini sejalan dengan hasil penelitian Apelbaum et al. (2003) yang menyimpulkan price premium berpengaruh terhadap perceived quality. Price premium cenderung mengacu pada hal-hal yang berkaitan dengan bagaimana suatu produk dapat dijual dengan harga yang tinggi. Setharaman et al. (2001) juga menyatakan bahwa price premium berhubungan dengan perceived quality.

Hasill penelitian ini menemukan pula adanya pengauh yang positif tetapi tidak signifikan dari variabel perceived price terhadap perceived quality. 
Kenyataan ini sejalan dengan temuan penelitian Apelbaum et al. (2003) yang mengemukakan harga bukanlah sinyal yang handal untuk memprediksi kualitas. Namun sebaliknya Peterson (1970) mengemukakan bahwa harga (perceived price) merupakan penentu utama bagi perceived quality. Hal senada juga dinyatakan oleh Setharaman et al. (2001). Secara empiris Lichtenstein et al. (1993), Agarwal dan Teas (2002) menemukan bahwa harga (perceived price) berhubungan positif dengan perceived quality. Yoo et al. (2000) juga menemukan bahwa harga (perceived price) berpengaruh positif terhadap perceived quality. Oleh karena itu harga (perceived price) secara positif mempengaruhi perceived quality, tetapi pengaruh tersebut tidak terlalu signifikan. Temuan yang agak berbeda ini dapat diakibatkan oleh tipikal konsumen yang sesnsitif terhadap harga tetapi brand minded. Artinya konsumen menjadi lebih peka terhadap harga yang diterima dari pemasar untuk produk yang memiliki nama merek terkenal seperti Sony.

Selanjutnya, hasil penelitian ini menunjukan adaya pengaruh yang positif tetapi tidak signifikan dari price deal terhadap perceived quality. Dickson dan Sawyer (1990) menemukan harga promosi (price deal) mampu memengaruhi konsumen secara positif dalam membeli produk tertentu. Hal senada juga diungkapkan oleh Winer (1986), Biswas dan Sherrell (1993) bahwa pilihan merk konsumen dapat dipengaruhi oleh harga referensi dari suatu merk. Sebaliknya menurut Winer (1986), harga yang berubah mencerminkan ketidak stabilan kualitas bagi konsumen. Menurut Raymond (Grewal et al. (1998) mengemukakan produsen tidak dapat bergantung pada harga promosi untuk menarik konsumen. Karena harga promosi bisa menjadi suatu kegagalan dalam mencapai penjualan, harga promosi malah dapat memerburuk citra keseluruhan dari suatu produk.

\section{PENUTUP}

\section{Kesimpulan}

Penelitian ini bertujuan untuk menganalisis faktor-faktor harga yang berpengaruh terhadap perceived quality produk elektronik merek Sony di Kota Ambon. Dari hasil penelitian ini dapat disimpulkan sebagai berikut :

1. Price premium berpengaruh secara positif dan signifikan terhadap perceived quality produk elektronik merek Sony di Kota Ambon.

2. Perceivde price berpengaruh secara positif tetapi tidak signifikan terhadap perceived quality produk elektronik merek Sony di Kota Ambon.

3. Price deal berpengaruh secara positif tetapi tidak signifikan terhadap perceived quality produk elektronik merek Sony di Kota Ambon.

Saran

Dari hasil penelitian ini, penulis dapat menyarankan :

1. Agar produsen dan pemasar produk elektronik merek Sony dalam menentukan kebijakan harga hendaknya senantiasa memertimbangkan faktor-faktor psikologis, sosial-budaya dan demografis konsumen akhirnya, sehingga harga dari produk yang ditawarkan mendapat responn yang positif dari pasar yang dituju. 
2. Penelitian di masa mendatang agar dapat memertimbangkan untuk mengikut-sertakan faktor-faktor harga yang lebih kompleks untuk bisa mendapatkan gambaran yang lebih menyeluruh tentang pengaruh faktorfaktor harga terhadap perceived quality.

\section{DAFTAR PUSTAKA}

Aaker, David A. 1991. Managing Brand Equity, New York : Free Press.

Agarwal, Sanjeev dan Teas, R. Kenneth. 2002. Cross-national applicability of a perceived quality model, Journal of Product \& Brand Management, Vol. 11 No. 4, 213-236.

Apelbaum, Eidan, Gersiner, Eltan dan Naik, Prasad A. 2003. The effects of expert quality evaluations versus brand name on price premiums, Journal of Product \& Brand Management, Vol. 12 No. 3, 154-165.

Baldauf, Artur, Cravens, Karens S. dan Binder, Gudrun. 2003. Performance consequences of brand equity management : evidence from organizations in the value chain, Journal of Product \& Brand Management, Vol. 12 No. 4, 220-236.

Biswas, Abhijit dan Sherrell, Daniel L., 1993. The influence of product knowledge and brand name on internal price standards on confidence, Psychology \& Marketing, Vol 10, No. 1, 31-46.

Blattberg, Robert C., dan Wisniewski, Kenneth J., 1989. Price-induced patterns of competition, Marketing Science, Vol. 8 No. 4, 291-309.

Chay, R.F., 1991. How marketing researchers can harness the power of brand equity, Marketing Research : a Magazine of Management and Applications, Vol 9 (June), 30-37.

Chen, Arthur Cheng-Hsui, 2001. Using free association to examine the relationship between the characteristics of brand associations and brand equity, Journal of Product \& Brand Management, Vol. 10 No. 7, 439- 451.

Cobb-Walgren, C.J., Ruble, Cynthia A, dan Donthu, Naveen, 1995. Brand equity, brand preference, and purchasing intent, Journal o0f Advertising, Vol. 24 No. 3, 25-40.

Crimmins, J.C., 1992. Better measurement and management of brand value, Journal of Advertising Research, Vol. 32 (July/August), 107-117.

Dawar, Niraj dan Parker, Philip, 1994. Marketing universals : consumers' use of brand name, price, physical appearance, and retailer reputation as signals of product quality, Journal of Marketing, Vol. 58 (April 1994), 81-95.

Del Rio, A. Belen, Vazquez, Rodolfo, dan Iglesias, Victor. 2001. The roleof the brand name in obtaining differential advantages, Journal of Product $\mathcal{E}$ Brand Management, Vol. 10, No. 7, 452-465.

Dickson, Peter R., dan Sawyer, Alan G., 1990. The price knowledge and search of supermarket shoppers, Journal of Marketing, Vol. 54 (July), 42-53.

Dodds, William B., Monroe, Kent B. dan Grewal, Dhruv, 1991. Effects of price, brand, and store information on buyers' product evaluations, Journal of Marketing Research, Vol. 28 (August), 307-319. 
Farquhar, Peter H. 1989. Managing brand equity, Marketing Research, Vol. 1 (September), 24-33.

Ferdinand, Augusty. 2006. Metode Penelitian Manajemen, Semarang: Badan Penerbit Universitas Diponegoro.

Grewal, Dhruv, Krishnan, R., Baker, J., dan Norin, Norm. 1998. The effect of store name, brand name and price discounts on consumers' evaluations and purchase intentions, Journal of Retailing, Vol. 74, No. 3, 331-352.

Gupta, Sunil. 1988. Impact of sales promotion on when, what, and how much to buy", Journal of Marketing Research, Vol. 25 (November), 342- 355.

Hair, J.F., Anderson, R.E., Tatham, R.L., dan Black, W.C., 1998. Multivariate Data Analysis, New Jersey: Prentice-Hall.

Kamakura, Wagner dan Russel, Gary, 1993. Measuring brand value with scanner data, International Journal Research in Marketing, Vol. 10 (March), 922.

Keller, Kevin Lane. 1993. Conceptualizing, measuring, and managing customerbased brand equity, Journal of Marketing, Vol. 57, No. 1, 1-22.

Lichtenstein, D.R., Ridgway, N.M. dan Netemeyar, R.G., 1993. Price perception and consumer shopping behavior : a field study, Journal of Marketing Research, Vol. 30 (May), 234-245.

Myers, Chris A., 2003. Managing brand equity : a look at the impact of attributes", Journal of Product E Brand Management, Vol. 12, No. 1, p. 39- 51.

Peterson, Robert A., 1970. The price-perceived quality relationship : experimental evidence, Journal of Marketing Research, Vol. 7 (November), 525-528.

Rao, Akshay R., dan Monroe, Kent B. 1989. The effect of price, brand name, and store name on buyers' perception of product quality : an integrative review, Journal of Marketing Research, Vol. 26 (August), 351- 357.

Setharaman, A., Bin Mohd Nadzir, Zainal Azlan dan Gunalan, S., 2001. A conceptual study on brand valuation, Journal of Product $\mathcal{E}$ Brand Management, Vol. 10 No. 4, 243-256.

Winer, R.S., 1986. A reference price model of brand choice for frequently purchased product, Journal of Consumer Research, Vol. 13 (September), 250256.

Yoo, Boonghee, Donthu, Naveen dan Lee, Sungho. 2000. An examination of selected marketing mix elements and brand equity", Academy of Marketing Science Journal, Vol. 28, No. 2, 195-211.

Zeithaml, V.A. 1988. Consumer perceptions of price, quality, and value : a means-end model and synthesis of evidence, Journal of Marketing, Vol. 52 (July), 2-22. 


\title{
Penanggung Jawab \\ Ambo Asse
}

\section{Ketua/}

M. Wahyuddin Abdullah

\author{
Dewan Editor \\ Alim Syariati \\ Rusdi Prayoga \\ Andi Mulia \\ Rusnawati
}

\author{
Mitra Bestari/Reviewer \\ Ambo Asse (UIN Alauddin Makassar), \\ Firman Menne (Universitas Bosowa Makassar) \\ Suwandi Ng (Universitas Atma Jaya Makassar), \\ Agus Salim (ISEI Sul-Sel), \\ Rika Dwi Ayu Parmitasari (UIN Alauddin Makassar), \\ Ahmad Efendi (UIN Alauddin Makassar), \\ Awaluddin (UIN Alauddin Makassar), \\ Okta Nofri (UIN Alauddin Makassar), \\ Eka Suhartini (UIN Alauddin Makassar), \\ Akil Rahman (UIN Alauddin Makassar),
}

\author{
Sekretaris Penyunting \\ Rusmawandi Rara \\ Nurhikma Hawabaja \\ Roshani
}

\author{
JURNAL MINDS \\ Pusat Dokumentasi dan Publikasi IImiah \\ Jurusan Manajemen Fakultas Ekonomi dan Bisnis Islam UIN Alauddin \\ JI. Sultan Alauddin No. 33 Samata-Gowa Sul-Sel -- INDONESIA \\ Telp/HP. 081355774774, 081241840208, Fax. (0411) 8221400 \\ Website OJS: http://journal.uin-alauddin.ac.id/index.php/minds \\ Email: minds@uin-alauddin.ac.id
}




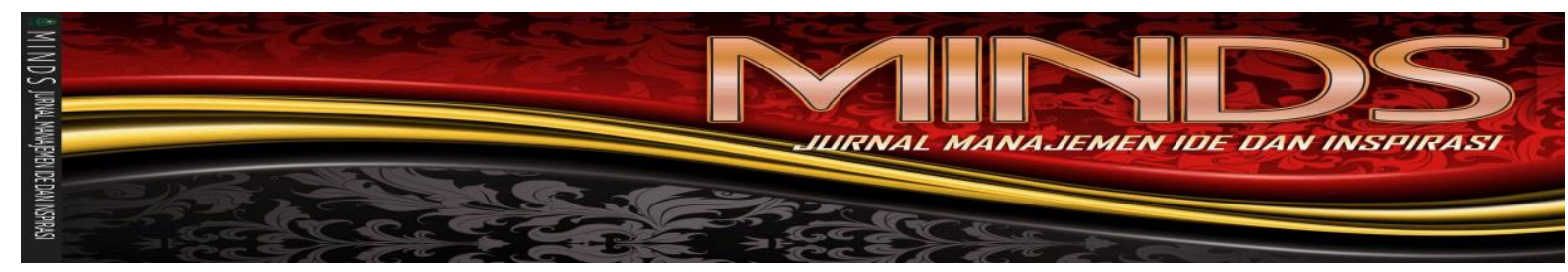

\section{KRITERIA TULISAN}

1. Panjang tulisan minimal 10 halaman dan maksimal 15 halaman

2. Menggunakan huruf Book Antiqua, font 12 , spasi 1, margin atas-bawah $3 \mathrm{~cm}$, kiri-kanan $2.54 \mathrm{~cm}$.

3. Tulisan dapat berupa hasil penelitian kuantitatif (diutamakan), penelitian kualitatitif, dan kajian teoritis dalam bidang Manajemen dengan penguatan pada integrasi keislaman.

4. Identitas penulis meliputi: nama penulis tanpa gelar, nama dan alamat afiliasi, dan alamat email penulis (contoh Alim Syariati, Fakultas Ekonomi dan Bisnis Islam UIN Alauddin, JI. HM. Yasin Limpo, NO. 63 Samata-Gowa, alim.syariati@uin-alauddin.ac.id).

5. Komposisi tulisan harus mengikuti pola berikut:

a. Judul

b. Abstrak (bahasa Indonesia dan bahasa Inggris) maksimal 150 kata dan kata kunci 3-5 kata

c. Pendahuluan (Yang didalamnya menyinggung mengenai masalah penelitian)

d. Tinjauan teoritis

e. Metode penelitian

f. Pembahasan

g. Penutup

h. Daftar pustaka

Buku: Hartono, Jogiyanto, 2004. Metodologi Penelitian Bisnis: Salah Kaprah dan pengalaman-pengalaman. Edisi 2004/2005. BPFE, Yogyakarta

Jurnal: Barney, Jay B. 1995. Looking Inside Competitive Advantage. Academy of Management, pp. 49-61

Penelitian Tidak Publikasi: Minimal sumber referensi berasal dari disertasi S3 (tapi tidak dianjurkan), dengan mengikuti format di atas

6. Menggunakan Innote

7. Waktu penting dalam penerbitan Jurnal berkala IImiah Minds, yaitu bulan Maret- Mei untuk terbitan pertama tahun berjalan, dan Oktober-November untuk terbitan kedua tahun berjalan melalui online journal system (OJS) yang bisa diakses melalui laman http://journal.uin-alauddin.ac.id/index.php/minds. Pertanyaan terkait jurnal Minds bisa disampaikan melalui email: minds@uin-alauddin.ac.id atau alim.syariati@uinalauddin.ac.id 